\title{
Use of Organoids Technology on Study of Liver Malignancy
}

\begin{abstract}
The study on liver cancer has been performed in clinical medicine and medical science for a long time. Within the few recent years, there are many new emerging biomedical technologies that help better assess on the liver cancer. Of several new technologies, the advanced cell technologies for the assessment of liver cancer, organoids technology is very interesting. In fact, the organoids is an advanced cell research technique that can be useful for studying of many medical disorders. Organoids can be applied for study on the pathophysiology of many cancers. The application for studying on liver cancer is very interesting issue in hepatology. In this short article, the author summarizes and discusses on applied organoids technology for studying on various kinds of liver cancers. The application can be seen on primary hepatocellular carcinoma, metastatic cancer, cholangiocarcinoma, hepatoblastoma, as well as other rare liver cancers.
\end{abstract}

Keywords: Liver, organoids, malignancy

\section{Introduction}

Cell is the structures of life, and it is the smallest unit of every living thing. The life starts from cell. At least, the living thing has to have a cell. The development of cell is very important for life, and the development of cell is a necessary step for completeness of life. The defect on development can be expected and this is the fundamental problem that can further cause the abnormality in life of the living things. To assess the development problem can provide the answer to many complex medical disorders. In fact, the basic pathophysiology of any medical disorder can be explained from the original point at the cellular step. Hence, the cellular study is the important step for study on pathophysiology in medicine. ${ }^{[1]}$ Although there are many ways to assess the pathophysiology in medical disorder, the study at cell by means of cellular technology is still a requirement.

At present, there are several new biomedical technologies. Several new advanced cell technologies are available. Those new technologies can help the medical scientist to deeply understand the cellular pathological development mechanism. The construction of cell model to modeling the disorder is the big advent

This is an open access journal, and articles are distributed under the terms of the Creative Commons Attribution-NonCommercial-ShareAlike 4.0 License, which allows others to remix, tweak, and build upon the work non-commercially, as long as appropriate credit is given and the new creations are licensed under the identical terms.

For reprints contact: reprints@medknow.com in cellular technology. This approach can help scientist study of the developmental pathophysiology of the complex medical disorders. $^{[1]}$ Of several complex medical disorders, cancerous disorder is the important deadly medical problem group. This problem can be seen worldwide and is still the leading cause of death of the world population. It can be said that we do largely not know on the pathophysiology of cancer. Very limited knowledge is available the basic fundamental developmental pathophysiology of cancer cell. ${ }^{[2]}$ As noted by Dormoy et al., the developmental pathways involved in carcinoma growth identification can be helpful in understanding the molecular mechanisms of malignancy. ${ }^{[2]}$ In addition, the knowledge can also lead to the improvement of cell based treatment of the disorders.

Classically, an in vitro experiment on the cancerous tissue is the basic technique for the study of the pathophysiology of cancer. However, this cannot probe into the cellular level. The coming of the new molecular technology might be an important part for understanding of the molecular composition and genetic background of cancer; however, it does not directly answer the question on cellular abnormality. The cell pathologist and scientist continuously develop new cell technologies to serve the need for the advanced techniques to cell

How to cite this article: Joob B, Wiwanitkit V. Use of organoids technology on study of liver malignancy. Indian J Med Paediatr Oncol 2018;39:499-502.

\section{Beuy Joob, Viroj Wiwanitkit ${ }^{1}$}

Sanitation 1 Medical Academic Center, Bangkok, Thailand, ${ }^{\prime}$ Department of Biological Science, Joseph Ayo Babalola University, Ilara-Mokin, Nigeria

Address for correspondence: Dr. Beuy Joob, Sanitation 1 Medical Academic Center, Bangkok, Thailand.

E-mail: beuyjoob@hotmail.com

Access this article online

Website: www.ijmpo.org

DOI: 10.4103/ijmpo.ijmpo_126_17 Quick Response Code:

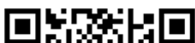


pathophysiology clarification. The construction of tissue model has been done for several years. Several cell cultures are available for cancer study. Nevertheless, the limitation of the cell culture, lack of reality, is the basic problem for using cell culture in oncological study. A more complex technique that can be applied and represent the real situation of the cellular component is healthy and cancerous situations are still required. How to derive the effective model is the big question in cell research. ${ }^{[1]}$

An interesting technology is "organoids". Organoids is an advanced cell technique that becomes a new widely used emerging cellular tool for advanced cell research. In brief, organoids is characterized as a three-dimensional (3D) structure which is generated by stem cell technique using adult or embryonic stem cells. This structural model can maintain many structural and functional features of their respective real organ. As noted by Dahl-Jensen and Grapin-Botton, organoids can answer the problem of lack of reality of the classical cell culture technique. ${ }^{[3]}$ The organoids can help reflect the developmental step from cell to overt phenotype in healthy and disorder situation. ${ }^{[3]}$ It can be a useful tool for help medical scientist closely monitor step by step of development and observe the starting point of the abnormality. ${ }^{[4]}$ A "dynamics of organ development, including the exciting prospect of observing aspects of human embryo development live"[3] is the core important concept of organoids that becomes the emerging useful tool for study on cellular pathophysiology.

As already noted, organoids can be used in pathophysiology assessment of several medical disorders. It can be applied for study of complex genetic disease, serious infection, and deadly cancer. Due to its use, it can be applied in several branches of medicine. ${ }^{[5-11]}$ The application in hepatology is also possible and will be further discussed in this short article. The aim of this review article does not present the original findings from research but to systematically summarize the available data on this topic. The overview of state of the art at present is given in Table 1 .

\section{Organoids for Study of Liver Cancer}

As already mentioned, the use of organoids in the assessment of developmental pathophysiology is confirmed and applied in several branches of medicine. ${ }^{[12]}$ Starting

Table 1: Summarization on present status of current organoids research for liver cancer

\begin{tabular}{ll}
\hline Type of liver cancer & Current research \\
\hline $\begin{array}{l}\text { Primary hepatocellular } \\
\text { carcinoma }\end{array}$ & $\begin{array}{l}\text { There are many ongoing researches for } \\
\text { this type of liver cancer }\end{array}$ \\
$\begin{array}{l}\text { Secondary hepatocellular } \\
\text { carcinoma }\end{array}$ & $\begin{array}{l}\text { Some reports on this type of cancer are } \\
\text { available }\end{array}$ \\
Cholangiocarcinoma & There is no report on this kind of cancer \\
\hline
\end{tabular}

from potent stem cell, the organoids development using advanced stem cell technology can help derive a model that can reflect the developmental process of organ in living things. ${ }^{[12]}$ In hepatology, the development of organoids model is already successful. As noted by $\mathrm{Xu}$ et al., "Together with efficient gene-editing protocol, organoids are emerging as powerful in vitro disease models.' ${ }^{[13]}$ In fact, the organoids model for liver is a new thing and actual new development in hepatology. ${ }^{[14,15]}$ At present, a small liver cell can be harvested and further used for cell processing by stem cell technology to provide liver organoids that can be able for further pathophysiology study. ${ }^{[14,15]}$ Mitaka and Ooe noted that the liver organoids is a realistic cellular model since it can represent the liver tissue's physiological and biochemical functions. ${ }^{[15]}$ Therefore, the study of several complex hepatic disorders can be based on the organoids model. This can be applied for several liver diseases including genetic, infectious, and cancer liver diseases.

In this short article, the author will focus on the cancerous problem. In fact, the study on liver cancer has been performed in clinical medicine and medical science for a long time. Within the past few years, there are many interesting new emerging advanced technologies that help better assess on the liver cancer. Of several new technologies, the advanced cell technologies for assessment of liver cancer, organoids technology is very interesting. As noted by Gao and Chen, "cancer 'organoid' culture conditions have been developed to establish in vitro growth of patient-derived samples at higher efficiency and they are very promising for large-scale drug screening and fundamental cancer biology research."[16] The author summarizes and discusses on applied organoids technology for studying on various kinds of liver cancers. The application can be seen on primary hepatocellular carcinoma, secondary liver cancer, metastatic liver cancer, cholangiocarcinoma, hepatoblastoma, as well as other rare liver cancers.

\section{Use of Organoids in Pre-liver Cancer Condition}

\section{Viral hepatitis}

Viral hepatitis is accepted as an important underlying cause of liver cancer. The hepatitis $\mathrm{B}$ virus and hepatitis $\mathrm{C}$ virus infections are confirmed as the major causes of liver cancer worldwide. ${ }^{[17,18]}$ The application of organoids technique in viral hepatitis is very interesting. Nevertheless, according to the literature review, there are extremely few reports on organoids research for viral hepatitis. A possible reason might be the advanced molecular technology already helps clarify most problem of pathophysiology of viral hepatitis. Nevertheless, there is a recent interesting research on using organoids technique to study the antiviral drug for hepatitis $\mathrm{C}$ virus infection in the case of Zika virus infection, ${ }^{[19]}$ which is an actual further application of organoids research on viral hepatitis. 


\section{Alcoholic hepatitis}

Focusing on alcoholic hepatitis, it is also accepted as an important cause of liver cancer. Similar to viral hepatitis, there are extremely limited reports on organoids research for alcoholic hepatitis. According to the record in database (Scopus and PubMed), there is no report on organoids research on alcoholic hepatitis.

\section{Use of Organoids in Different Kinds of Liver Cancer}

\section{Primary hepatocellular carcinoma}

Organoids research on primary hepatocellular carcinoma is an actual applied organoids technique in oncology. ${ }^{[20]}$ For hepatocellular carcinoma research, organoids can be used for the assessment on genetic backgrounds. In addition, the disease modeling can further be useful for finding a proper personalized cancer therapy planning. ${ }^{[21]}$ The first requirement that brings success for the use of organoids tool in primary hepatocellular carcinoma research is the success in the development of effective organoids model. For example, in 2006, there was a report on the successful development of a new liver organoids based on a functional human hepatocellular carcinoma cell line. ${ }^{[22]}$ The organoids model in that study also made use of mouse cell lines for generation. This model is the basic reference for further organoids development for primary hepatocellular research.

Another interesting model was proposed by Kobayashi et al. in 2013. ${ }^{[23]}$ Kobayashi et al. used advanced stem cell technology to manipulate hepatocytes and fibroblasts accompanied with primary hepatocellular carcinoma cell line to form the organoids model. ${ }^{[23]}$

In addition to the organoids model development, the actual applied of the developed model is very interesting. First, the study on genetic underlying of hepatocellular carcinoma is a good example of application of organoids technique for pathophysiological study of primary hepatocellular carcinoma. Crosas-Molist et al. studied on the interrelationship between oncogene and hepatoma by mean of organoids model and concluded the cellular pathophysiological mechanism of tumor aggressiveness of primary hepatocellular carcinoma. ${ }^{[2]}$ Second, the study on cancer therapy for primary hepatocellular carcinoma by organoids technique should also be mentioned. In fact, the attempt of using spheroids technique, which is a preorganoids development, for study in anticancerous agent has been published for many years. ${ }^{[25]}$ For organoids, Lu et al. recently reported on anticancer effect of triterpenoid preparation using organoids model. ${ }^{[26]} \mathrm{Lu}$ et al. found that triterpenoid preparation had strong cytotoxic effect and also identified drug-drug interaction according to the studied preparation. ${ }^{[26]}$ This report by Lu et al. ${ }^{[26]}$ is a good example of report from organoids technique that might be further useful in new anticancer drug search.

\section{Secondary liver cancer}

The secondary liver cancer, caused by cancer metastatic cells from other primary origin, due to other cancer is a common problem in oncology since the liver is the common site of cancer metastasis. Skardal et al. recently reported an interesting organoids technique research on secondary liver cancer. ${ }^{[27]}$ Skardal et al. reported the success in developed organoids model of secondary liver cancer due to colon cancer metastasis and mentioned for using the potential of in vitro $3 \mathrm{D}$ liver-tumor organoids for serving as a model for metastasis growth as well for assessment the response of malignant cells to present and newly launched drugs. ${ }^{[26]}$

\section{Metastatic liver cancer}

The metastasis of primary hepatocellular carcinoma is a common problem in advanced primary hepatocellular carcinoma. Metastatic liver cancer, caused by metastatic liver cancer cells in another organ, is difficult to manage in oncology. Although there is a success in organoids development for metastatic cancer model, such as model for metastatic colorectal cancer, ${ }^{[28]}$ there is still no report on the success on the development of organoids model of metastatic liver cancer.

\section{Cholangiocarcinoma}

Cholangiocarcinoma is a common biliary tract cancer. The intrahepatic cholangiocarcinoma is a deadly liver cancer with a poor prognosis. In tropical Southeast Asia, the relationship between cholangiocarcinoma and liver fluke infestation is confirmed. ${ }^{[29,30]}$ Focusing on the use of organoids model for cholangiocarcinoma research, there is still no report on success in the development of organoids model for cholangiocarcinoma.

\section{Hepatoblastoma}

Hepatoblastoma is an important kind of liver cancer seen in pediatric hepatology. The application of organoids research on this liver cancer is limited. Nevertheless, there is an interesting report on using spheroids technique. ${ }^{[31]}$ In that study, Kosaka et al. successfully used spheroid cultures of human hepatoblastoma cells for studying on alcoholic toxicity and development of cancer. ${ }^{[31]}$ The future organoids development can be referred to the basic information from the study by Kosaka et al. ${ }^{[31]}$

\section{Hepatic lymphoma}

Hepatic lymphoma is a rare type of liver cancer ${ }^{[32]}$ Although the development of organoids model for lymphoma is successful, ${ }^{[33]}$ there is still no application on organoids research for hepatic lymphoma.

\section{Conclusion}

Organoids is a new cellular technology with used on stem cell knowledge for modeling realistic model to reflect medical disorder. It can be useful for cellular 
developmental pathophysiology study. In hepatology research, the new advanced organoids tool can be very useful on the etiopathophysiology study of several liver problems including liver cancer. It is widely applied for studying on several precancer conditions and several kinds of liver cancer. The rapid progression of the cell biotechnology can be seen and this is very useful for liver cancer pathophysiology and therapeutic research. Although the development and maintenance of organoids is still a big technical problem for many settings, the use of this new cellular tool warrants further attempt of the medical scientist who works on liver cancer research to learn, develop, and use the organoids technique for hepatic cancer research and development. The organoids is an actual hope for the future in hepatology. Nevertheless, it is still far incomplete in terms of coverage of models. It should be well clarified that there are several types of organoid culture. Sometimes, the effectiveness of technique is due to the difference of transport phenomena and diffusion limitation. It is still the interesting topic for further study on required culture condition for the truly effective organoids.

\section{Financial support and sponsorship}

Nil.

\section{Conflicts of interest}

There are no conflicts of interest.

\section{References}

1. Simunovic M, Brivanlou AH. Embryoids, organoids and gastruloids: New approaches to understanding embryogenesis. Development 2017;144:976-85.

2. Dormoy V, Jacqmin D, Lang H, Massfelder T. From development to cancer: Lessons from the kidney to uncover new therapeutic targets. Anticancer Res 2012;32:3609-17.

3. Dahl-Jensen S, Grapin-Botton A. The physics of organoids: A biophysical approach to understanding organogenesis. Development 2017;144:946-51.

4. Clevers H. Modeling development and disease with organoids. Cell 2016;165:1586-97.

5. Schaper J. Effects of multiple ischaemic events on human myocardium - An ultrastructural study. Eur Heart J 1988;9 Suppl A:141-9.

6. Date S, Sato T. Mini-gut organoids: Reconstitution of the stem cell niche. Annu Rev Cell Dev Biol 2015;31:269-89.

7. Giandomenico SL, Lancaster MA. Probing human brain evolution and development in organoids. Curr Opin Cell Biol 2017;44:36-43.

8. Morizane R, Bonventre JV. Kidney organoids: A translational journey. Trends Mol Med 2017;23:246-63.

9. Ruggiu A, Cancedda R. Bone mechanobiology, gravity and tissue engineering: Effects and insights. J Tissue Eng Regen Med 2015;9:1339-51.

10. Barkauskas CE, Chung MI, Fioret B, Gao X, Katsura H, Hogan BL. Lung organoids: Current uses and future promise. Development 2017;144:986-97.

11. Hindley CJ, Cordero-Espinoza L, Huch M. Organoids from adult liver and pancreas: Stem cell biology and biomedical utility. Dev Biol 2016;420:251-61.
12. Jones JR, Zhang SC. Engineering human cells and tissues through pluripotent stem cells. Curr Opin Biotechnol 2016;40:133-8.

13. Xu AT, Tong JL, Ran ZH. Organoids derived from digestive tract, liver, and pancreas. J Dig Dis 2016;17:3-10.

14. Mitaka T. Reconstruction of hepatic organoid by hepatic stem cells. J Hepatobiliary Pancreat Surg 2002;9:697-703.

15. Mitaka T, Ooe H. Characterization of hepatic-organoid cultures. Drug Metab Rev 2010;42:472-81.

16. Gao D, Chen Y. Organoid development in cancer genome discovery. Curr Opin Genet Dev 2015;30:42-8.

17. Hemming AW, Berumen J, Mekeel K. Hepatitis B and hepatocellular carcinoma. Clin Liver Dis 2016;20:703-20.

18. Colpitts CC, Verrier ER, Baumert TF. Targeting viral entry for treatment of hepatitis B and C virus infections. ACS Infect Dis 2015;1:420-7.

19. Sacramento CQ, de Melo GR, de Freitas CS, Rocha N, Hoelz LV, Miranda $\mathrm{M}$, et al. The clinically approved antiviral drug sofosbuvir inhibits Zika virus replication. Sci Rep 2017;7:40920.

20. Wiwanitkit V. Organoids as a tool for hepatoma research. J Cancer Res Ther 2017. [In press].

21. Drost J, Clevers H. Translational applications of adult stem cell-derived organoids. Development 2017;144:968-75.

22. Saito M, Matsuura T, Masaki T, Maehashi H, Shimizu K, Hataba Y, et al. Reconstruction of liver organoid using a bioreactor. World J Gastroenterol 2006;12:1881-8.

23. Kobayashi A, Yamakoshi K, Yajima Y, Utoh R, Yamada M, Seki M. Preparation of stripe-patterned heterogeneous hydrogel sheets using microfluidic devices for high-density coculture of hepatocytes and fibroblasts. J Biosci Bioeng 2013;116:761-7.

24. Crosas-Molist E, Bertran E, Rodriguez-Hernandez I, Herraiz C, Cantelli G, Fabra À, et al. The NADPH oxidase NOX4 represses epithelial to amoeboid transition and efficient tumour dissemination. Oncogene 2017;36:3002-14.

25. Yip D, Cho CH. A multicellular 3D heterospheroid model of liver tumor and stromal cells in collagen gel for anti-cancer drug testing. Biochem Biophys Res Commun 2013;433:327-32.

26. Lu J, Zhang Y, Sun M, Liu M, Wang X. Comprehensive assessment of Cucurbitacin E related hepatotoxicity and drug-drug interactions involving CYP3A and P-glycoprotein. Phytomedicine 2017;26:1-10.

27. Skardal A, Devarasetty M, Rodman C, Atala A, Soker S. Liver-tumor hybrid organoids for modeling tumor growth and drug response in vitro. Ann Biomed Eng 2015;43:2361-73.

28. Xie BY, Wu AW. Organoid culture of isolated cells from patient-derived tissues with colorectal cancer. Chin Med J (Engl) 2016;129:2469-75.

29. Wilcox BA, Echaubard P. Balancing biomedical and ecological perspectives in research framing of liver fluke and cholangiocarcinoma in NE Thailand. Parasitol Int 2017;66:372-77.

30. Zheng S, Zhu Y, Zhao Z, Wu Z, Okanurak K, Lv Z. et al. Liver fluke infection and cholangiocarcinoma: A review. Parasitol Res 2017;116:11-9.

31. Kosaka T, Tsuboi S, Fukaya K, Pu H, Ohno T, Tsuji T, et al. Spheroid cultures of human hepatoblastoma cells (HuH-6 line) and their application for cytotoxicity assay of alcohols. Acta Med Okayama 1996;50:61-6.

32. Zheng J, Hou Y, Zhou R, Zhong D. Clinicopathological features of primary hepatic diffuse large B-cell lymphoma: A report of seven cases and a literature review. Int J Clin Exp Pathol 2015;8:12955-60.

33. Tian YF, Ahn H, Schneider RS, Yang SN, Roman-Gonzalez L, Melnick AM, et al. Integrin-specific hydrogels as adaptable tumor organoids for malignant B and T cells. Biomaterials 2015;73:110-9. 